\title{
EDITORIAL
}

\section{Blunted sensation of dyspnoea and near fatal asthma}

\author{
D.J. Eckert*,\#, P.G. Catcheside*,\#, R.D. McEvoy*,\#,
}

Asthmatic patients who experience an acute, severe attack requiring hospitalisation, intensive care admission or who die as a result of the attack make up a relatively small percentage of the total asthma population [1]. However, they contribute disproportionately to the human and economic cost of this disease. It has long been held that it should be possible to identify such individuals ahead of time in order to focus therapeutic efforts in their direction to reduce morbidity and mortality. Despite substantial research effort, this goal remains elusive. The impediments to progress in this area are considerable. First, there are no universally agreed diagnostic criteria for near fatal asthma (NFA) [1]. Perhaps not surprisingly therefore there have been no large scale prospective multicentre studies in unselected clinical populations to define the incidence of NFA and its relationship to fatal asthma [1]. Secondly, it appears from case control studies that multiple risk factors are likely involved. These include psychological and socioeconomic factors, poor asthma control, suppressed respiratory sensation and blunted chemoreceptor sensitivity [1-6]. Prior near-miss episodes are also predictive of subsequent NFA episodes and fatalities [7]. Thus far no reliable predictive equation or screening tool has been developed to identify patients at risk of NFA. Initial findings reported in this issue by BARREIRO et al. [8] offer some promise that assessment of dyspnoea at maximal exercise capacity could prove useful in this respect.

Accurate recognition of asthma symptoms is essential for prompting individuals with acute severe asthma to increase medication or seek medical assistance. Any factor that inhibits this process has the potential to increase asthma morbidity and mortality [3,4]. Perception of dyspnoea and the underlying mechanisms for its genesis are complex and incompletely understood [9,10]. Multiple sensory pathways and brain regions have been implicated [11-13]. Psychological factors may also impair respiratory sensation and contribute to poor asthma control [6].

In this issue of the European Respiratory Journal BARREIRO et al. [8] compared respiratory sensation in NFA patients and chronic severe asthmatics without NFA. The two groups had similarly impaired lung function (forced expiratory volume in one second $\sim 60 \%$ predicted). The investigators observed trends for blunted perception of dyspnoea following a six-min walk and inspiratory threshold loading, and demonstrated significant blunting of dyspnoea at rest and after peak exercise on a cycle ergometer. These findings extend, and are consistent with earlier reports of blunted respiratory sensation during external resistive loading and bronchoconstriction in

\footnotetext{
*Adelaide Institute for Sleep Health and Dept of Respiratory Medicine, Repatriation General Hospital, Daw Park, "School of Molecular and Biomedical Science, Discipline of Physiology, University of Adelaide, and "Dept of Medicine, Flinders University, Bedford Park South Australia, Australia.

Correspondence: D.J. Eckert, Adelaide Institute for Sleep Health, Repatriation General Hospital, Daw Park, South Australia, 5041, Australia. Fax: 61 882776890. E-mail: danny.eckert@rgh.sa.gov.au
}

subjects with NFA [3, 14-16]. They did not examine respiratory sensation during acute bronchoconstriction but their findings across a range of respiratory stimuli strongly suggest a generalised blunting of respiratory sensation amongst patients with a history of NFA. It would have been very interesting to know if other sensory modalities were also impaired. WEBSTER and COLRAIN [17], recently reported blunted cortical evoked potential P3 responses (a marker of cognitive processing) elicited by respiratory and auditory stimuli in adults with asthma since childhood compared to healthy controls. This raises the possibility of a more generalised disturbance of higher sensory functioning in asthma. In children with a history of NFA respiratory afferent neural transmission may also be adversely affected lower in the neuraxis [18]. The integrity of nonrespiratory sensory function in NFA versus non-NFA remains unexplored.

These findings raise several important and interrelated questions. Is blunting of perception an inherited or acquired trait? If inherited, what is the genetic basis for the abnormality? If acquired, what is it about the condition of asthma that leads to blunting of perception? Is it adaptation of sensory pathways or could exposure to hypoxia during exacerbations play a role by producing a more general disturbance of sensory processing? Can the acquired deficits be reversed? Finally, but perhaps most importantly, is the reported association between blunted respiratory sensation and near-fatal or fatal asthma sufficiently strong to recommend the identification and special treatment of such patients in clinics?

One possible cause of blunted respiratory sensation amongst NFA patients are previous episodes of hypoxemia related to acute bronchoconstriction. Although acute brief hypoxia stimulates ventilation and elicits the symptom of dyspnoea [9], hypoxia when sustained for $>10$ min appears to impair respiratory sensations of external resistive loads in healthy individuals and in asthmatics $[19,20]$. Symptoms of dyspnoea during methacholine-induced bronchoconstriction are also suppressed by $25-30 \%$ immediately after sustained hypoxia [19]. NFA patients may be more prone to develop hypoxemia during acute asthma attacks because of depressed ventilatory responsiveness to hypoxemia $[3,21]$, a trait that is potentially genetically predetermined [22]. It is not known whether repeated or prolonged exposure to hypoxia in severe or poorly controlled asthmatics causes further blunting of respiratory and other sensory pathways. Children with chronic severe asthma do not appear to display signs of neuropsychological impairment as a result of hypoxia [23]. However, chronic hypoxia has been proposed to contribute to impaired sensory afferent transmission in severe chronic obstructive pulmonary disease [24]. Recent evidence suggests repeated exposure to hypoxia may lead to persistent changes in the output of the respiratory pattern generator [25], which could also affect respiratory sensation [26].

An appreciation of factors that might augment or reverse blunted sensation in asthma is also potentially important, both for the interpretation of experimental findings and for 
assessing their therapeutic potential in NFA. Inhaled corticosteroids have recently been demonstrated to heighten the sensation of dyspnoea in asthma [27, 28]. Earlier research suggests theophylline (a higher centre and muscle stimulant) may increase perception of asthma [29]. In light of these findings, the influence of medications taken by the two groups of asthmatic patients examined by BARREIRO et al. [8] needs to be carefully considered. BARREIRO et al. [8] reported high dosage use of these medications in the control group during the year prior to study. The medication history amongst the NFA group was not reported. If inhaled corticosteroids or theophylline were used more frequently or at higher dose in the non-NFA than the NFA group (with overall more asthma stability), this may have contributed to the observed differences in respiratory sensation. Future studies investigating respiratory sensation and asthma should ensure that asthma control and medication usage is fully documented in all subjects and matched between index cases and controls.

If it is assumed that patients with NFA in the study by BARREIRO et al. [8] and in previous studies [3, 14-16] had blunting of respiratory sensation, not explained by different medication regimens, it is possible that such blunting may be amenable to pharmacological manipulation. In addition to inhaled corticosteroids and theophylline, doxapram appears to increase hypoxic chemosensitivity and sensations of dyspnoea [30]. Its effects might be usefully investigated in this patient population. It is now clear that many areas of the central nervous system are "plastic". Recent evidence supports sustained improvements in sensory and motor function can be induced by repeated sensory and motor cortical excitation [31, 32]. It is conceivable that similar techniques could be used to heighten sensory perception in NFA.

BARREIRO et al. [8] present sensitivity and specificity data supporting a potential role for exercise test dyspnoea scores to help identify patients at risk of near fatal or fatal asthma attacks. Whilst they caution that the expense of such an approach may prove prohibitive, further caution is warranted given the limited data from which to gauge the utility of such a test in a more realistic clinic population. In the study of BARREIRO et al. [8], data are only available from a small, highly selected population with a known history of near fatal asthma and a similar number of case-controls. The pretest probability of near fatal asthma was therefore $\sim 50 \%$. This is likely much higher than in a prospective, unselected clinic population or even a subgroup stratified according to other risk factors, such as baseline forced expiratory volume in one second, where the actual risk of near or fatal-asthma attack would be unknown without long-term follow-up, but is likely to be low [1]. The real utility of such a test will not be known until larger prospective studies are available to show the full receiver operator characteristics and the likelihood ratios at appropriate cut-offs. Prospective analysis would also ensure that the control group, with significant chronic asthma yet heightened sensations of dyspnoea following exercise compared to the near fatal asthma group, do not develop life threatening episodes as the test would imply. This may be particularly important given the uncertainty of disease duration in the two study groups BARREIRO et al. [8] examined. Additionally, dyspnoea sensation during exercise testing may not be a valid prediction tool in children with severe asthma who may actually have higher perception of dyspnoea following exercise [33]. Nevertheless, the work of BARREIRO et al. [8] and others [16] offers promise that simple tests of respiratory sensation may assist in the early identification and more aggressive management of patients who might be at particular risk of near or fatal asthma.

\section{References}

1. McFadden ER Jr. Acute severe asthma. Am J Respir Crit Care Med 2003; 168: 740-759.

2. Campbell DA, McLennan G, Coates JR, et al. A comparison of asthma deaths and near-fatal asthma attacks in South Australia. Eur Respir J 1994; 7: 490-497.

3. Kikuchi Y, Okabe S, Tamura G, et al. Chemosensitivity and perception of dyspnoea in patients with a history of nearfatal asthma. N Engl J Med 1994; 330: 1329-1334.

4. Magadle R, Berar-Yanay N, Weiner P. The risk of hospitalization and near-fatal and fatal asthma in relation to the perception of dyspnoea. Chest 2002; 121: 329-333.

5. Turner MO, Noertjojo $\mathrm{K}$, Vedal $\mathrm{S}$, Bai $\mathrm{T}$, Crump $\mathrm{S}$, Fitzgerald JM. Risk factors for near-fatal asthma. A case-control study in hospitalized patients with asthma. Am J Respir Crit Care Med 1998; 157: 1804-1809.

6. Boulet LP, Deschesnes F, Turcotte H, Gignac F. Near-fatal asthma: clinical and physiologic features, perception of bronchoconstriction, and psychologic profile. J Allergy Clin Immunol 1991; 88: 838-846.

7. Burgess C, Pearce N, Thiruchelvam R, et al. Prescribed drug therapy and near-fatal asthma attacks. Eur Respir J 1994; 7 : 498-503.

8. Barreiro E, Gea J, Sanjuás C, Marcos R, Broquetas J, Milic-Emili J. Dyspnoea at rest and at the end of different exercises in patients with near-fatal asthma. Eur Respir $J$ 2004; 219-225.

9. American Thoracic Society. Dyspnoea. Mechanisms, assessment, and management: a consensus statement. Am J Respir Crit Care Med 1999; 159: 321-340.

10. Killian KJ. Measurements of dyspnoea during bronchoconstriction. Eur Respir J 1999; 13: 943-946.

11. Guz A. Respiratory sensations in man. Br Med Bull 1977; 33: 175-177.

12. Peiffer C, Poline JB, Thivard L, Aubier M, Samson Y Neural substrates for the perception of acutely induced dyspnoea. Am J Respir Crit Care Med 2001; 163: 951-957.

13. Gozal D, Omidvar O, Kirlew KA, et al. Identification of human brain regions underlying responses to resistive inspiratory loading with functional magnetic resonance imaging. Proc Natl Acad Sci USA 1995; 92: 6607-6611.

14. Kifle Y, Seng V, Davenport PW. Magnitude estimation of inspiratory resistive loads in children with life-threatening asthma. Am J Respir Crit Care Med 1997; 156: 1530-1535.

15. Ruffin RE, Latimer KM, Schembri DA. Longitudinal study of near fatal asthma. Chest 1991; 99: 77-83.

16. Julius SM, Davenport KL, Davenport PW. Perception of intrinsic and extrinsic respiratory loads in children with life-threatening asthma. Pediatr Pulmonol 2002; 34: 425433 .

17. Webster KE, Colrain IM. P3-specific amplitude reductions to respiratory and auditory stimuli in subjects with asthma. Am J Respir Crit Care Med 2002; 166: 47-52.

18. Davenport PW, Cruz M, Stecenko AA, Kifle Y. Respiratoryrelated evoked potentials in children with life-threatening asthma. Am J Respir Crit Care Med 2000; 161: 1830-1835.

19. Eckert DJ, Catcheside PG, Smith JH, Frith PA, McEvoy RD. Hypoxia suppresses symptom perception in asthma. Am $J$ Respir Crit Care Med 2004; 169: 1224-1230.

20. Orr RS, Jordan AS, Catcheside P, Saunders NA, McEvoy RD. Sustained isocapnic hypoxia suppresses the perception of the magnitude of inspiratory resistive loads. J Appl Physiol 2000; 89: 47-55.

21. Hudgel DW, Capehart M, Hirsch JE. Ventilation response and drive during hypoxia in adult patients with asthma. Chest 1979; 76: 294-299.

22. Kobayashi S, Nishimura M, Yamamoto M, Akiyama Y, Kishi F, Kawakami Y. Dyspnoea sensation and chemical control of breathing in adult twins. Am Rev Respir Dis 1993; 147: 1192-1198.

23. Bender BG, Belleau L, Fukuhara JT, Mrazek DA, Strunk 
RC. Psychomotor adaptation in children with severe chronic asthma. Pediatrics 1987; 79: 723-727.

24. Atis S, Ozge A, Sevim S. The brainstem auditory evoked potential abnormalities in severe chronic obstructive pulmonary disease. Respirology 2001; 6: 225-229.

25. Morris KF, Gozal D. Persistent respiratory changes following intermittent hypoxic stimulation in cats and human beings. Respir Physiol Neurobiol 2004; 140: 1-8.

26. Killian KJ, Bucens DD, Campbell EJ. Effect of breathing patterns on the perceived magnitude of added loads to breathing. J Appl Physiol 1982; 52: 578-584.

27. Salome CM, Reddel HK, Ware SI, et al. Effect of budesonide on the perception of induced airway narrowing in subjects with asthma. Am J Respir Crit Care Med 2002; 165: $15-21$.

28. Bijl-Hofland ID, Cloosterman SG, Folgering HT, van den Elshout FJ, van Weel C, van Schayck CP. Inhaled corticosteroids, combined with long-acting beta(2)-agonists, improve the perception of bronchoconstriction in asthma. Am J Respir Crit Care Med 2001; 164: 764-769.

29. Higgs CM, Laszlo G. Influence of treatment with beclomethasone, cromoglycate and theophylline on perception of bronchoconstriction in patients with bronchial asthma. Clin Sci (Lond) 1996; 90: 227-234.

30. Ebihara S, Ogawa H, Sasaki H, Hida W, Kikuchi Y. Doxapram and perception of dyspnoea. Chest 2002; 121: 1380-1381.

31. Uy J, Ridding MC, Hillier S, Thompson PD, Miles TS. Does induction of plastic change in motor cortex improve leg function after stroke? Neurology 2003; 61: 982-984

32. McKay DR, Ridding MC, Thompson PD, Miles TS. Induction of persistent changes in the organisation of the human motor cortex. Exp Brain Res 2002; 143: 342-349.

33. Rietveld S, Colland VT. The impact of severe asthma on schoolchildren. J Asthma 1999; 36: 409-417. 